\title{
Control of the solid solution decay by heat treatments of deformed niobium-titanium alloys
}

\author{
L.A.Chirkina, O.I.Volchok, M.B.Lazareva, \\ V.S.Okovit, G.E.Storozhilov
}

\author{
NSC "Kharkiv Institute of Physics and Technology", \\ 1 Akademicheskaya Str., 61108 Kharkiv, Ukraine
}

Received June 12, 2013

The features of phase transformation kinetics in solid binary solutions have been studied to show the expediency and efficiency of determining the DMS dependence on the annealing time $G(\tau)$ to optimize the heat treatment procedure for superconducting $\mathrm{Nb}-\mathrm{Ti}$ alloys. The advantages of the $G(\tau)$ determination method, compared with a technique usually applied for critical current $J_{c}(\tau)$ measuring, are substantiated. By this method a rapid "in situ" determination of the optimum heat treatment time corresponding to the point of maximum in the $G(\tau)$ curve is provided.

В рамках рассмотрения особенностей кинетики фазовых превращений двойных твердых растворов показана целесообразность и әффективность определения зависимости динамического модуля сдвига от времени отжига $G(\tau)$ для оптимизации режима термообработки сверхпроводящих ниобий-титановых сплавов. Обоснованы преимущества метода определения $G(\tau)$ по сравнению с обычно применяемой методикой измерения критического тока $J_{c}(\tau)$. При этом обеспечивается "in situ" экспрессное определение оптимального времени термообработки, которое соответствует точке максимума на зависимости $G(\tau)$.

Управління процесом розпаду твердого розчину при термообробках деформованих ніобій-титанових сплавів. Л.А.Чиркина, О.И.Волчок, М.Б.Лазарева, В.С.Оковит, Г.Е.Сторожилов.

В рамках розгляду особливостей кінетики фазових перетворень подвійних твердих розчинів показано доцільність і ефективність визначення залежності динамічного модуля зрушення від часу відпалу $G(\tau)$ для оптимізації режиму термообробки надпровідних ніобій-титанових сплавів. Обгрунтовано переваги методу визначення $G(\tau)$ у порівнянні із зазвичай вживаною методикою вимірювання критичного струму $J_{c}(\tau)$. При цьому забезпечуться "in situ" експресне визначення оптимального часу термообробки, яке відповідає точці максимуму на залежності $G(\tau)$.

\section{Introduction}

At the present time the most commonly used functional materials designed for superconducting magnetic systems are niobium-titanium alloys. This is due to their high deformation capacity permitting to realize structure-phase transformations by subsequent heat treatments (HT) providing high superconducting and mechanical properties. In the studies on $\mathrm{Ni}-\mathrm{Ti}$ alloys [1-4] the structural criteria for obtaining high values of the critical current density $\left(J_{c}\right)$ were determined. To date record values of $J_{c}$ were obtained using the mechanical heat 
treatment proposed in [5]. The main structure elements conditioning the high critical current achievement are textured fine-dispersed $\alpha-\mathrm{Ti}$ particles which size correlates with the magnetic vortex coherent length, that provides an effective magnetic flux pinning [6,7]. In the case of fixed annealing temperature, ensuring an active decay of the $\beta$-solid solution in the deformed $\mathrm{Nb}-$ Ti alloys the main parameter of HT optimization is the annealing time $(\tau)$. Usually, $\alpha-\mathrm{Ti}$ phase formation during $\mathrm{HT}$ of $\mathrm{Nb}-\mathrm{Ti}$ alloys is controlled by measuring $J_{c}$ as a function of $\tau$ [7]. It is a difficult process because of frequent $\mathrm{HT}$ interruptions and subsequent $J_{c}$ measurements on the samples under cryogenic conditions $(T=4.2 \mathrm{~K})$. Besides, the determination of optimum annealing time becomes complicated and longer for lack of critical currents in the $J_{c}(\tau)$ curve (e.g. maximum points) characterizing the completion of solid-solution decay stages. For other available methods of control of the solid solution decay processes using the structural sensitivity of parameters being measured [8-11], the HT procedure should be interrupted too. Moreover, these methods give the information, mainly, about structural changes in the localized microvolumes.

It is well known that the material elastic modulus presents a volumetric precision characteristic possessing a high sensitivity to the alloy chemical composition change as a result of solid solution decay [12]. Depending on the relation between the bonding forces of dissolved material atoms and solvent atoms, as well as, between the interatomic forces in the solvent lattice, the change in the solid solution chemical composition can increase or decrease the material elastic modulus.

The present paper gives a physical rationale for expediency of controlling the process of $\beta$-solid solution decay and determining the optimum time of HT in the deformed niobium-titanium alloys by measurement of dynamic modulus of shear (DMS) just in the annealing process.

\section{Material and methods}

A material under study was niobium-titanium alloy NT-50 (48 wt.\% Ti) in the form of wire samples obtained by overall deformation of the ingot [1] and subsequent drawing at $77 \mathrm{~K}$ to the finite diameter of $0.5 \mathrm{~mm}$. Application of the drawing under cryogenic $(77 \mathrm{~K})$ conditions promotes sub- stantially the process of $\beta$-solid solution decay, i.e. reduces the heat treatment time for obtaining high critical current values. The electron microscopic investigations have shown [4] that the features of NT-50 alloy structure state after cryogenic drawing include an increased density of deformation defects, a high dispersion of $\beta$-phase structure, high and distinct nonuniform fields of internal stresses. These factors can promote to significant increase of a number of potential points for $\alpha-T i$ particle nucleation under conditions of subsequent annealing and acceleration of $\beta$-solid solution decay process.

Next annealings were carried out at $T=663 \mathrm{~K}$, being effective temperature for $\beta$-solid solution decay in the HT-50 alloy [1], in the course of which the dynamic modulus of shear $G(\tau)$ was measured as a function of the critical current density $J_{c}(\tau)$.

DMS was determined using a device for measuring the internal friction and the elastic modulus [13] at frequency of $0.5 \mathrm{~Hz}$ with oscillation amplitude of $2.0 \cdot 10^{-5}$, corresponding to the amplitude-independent internal friction, at $T=663 \mathrm{~K}$ in vacuum of $10^{-3} \mathrm{~mm} \mathrm{Hg}$. In the course of HT every $3 \mathrm{~h}$ the $G(\tau)$ dependence was measured without disturbing the annealing regime. The DMS values were determined by the formula: $G=$ $128 \pi L I f^{2} / d^{4}$, where $L$ is the sample length, $d$ - sample diameter, $I$ - moment of inertia of a torsion pendulum, $f$ - oscillation frequency. The accuracy of $G$ measurement was $0.1 \%$, the measurement time did not exceed $5 \mathrm{~min}$.

To measure $J_{c}(\tau)$ a roll of the wire, deformed by the above-mentioned procedure, was annealed in the vacuum furnace $\left(10^{-3} \mathrm{~mm} \mathrm{Hg}\right)$ at $663 \mathrm{~K}$. Every $10 \mathrm{~h}$ the furnace was cooled to the room temperature then the sample was cut off from the roll. On the sample obtained the critical current was measured by the resistive method at $4.2 \mathrm{~K}$ in the transverse magnetic field with a strength of $5 \mathrm{~T}$. Appearance of potential difference equal to $1 \mu \mathrm{V} / \mathrm{cm}$ served as a criterion for critical current recording. Every operation cycle (annealing interruption, wire roll cooling, sample cutting and $J_{c}$ measuring) lasted not less than $5 \mathrm{~h}$ and repeated as long as decrease of the critical current value on the $J_{c}(\tau)$ curve was fixed. 


\section{Results and discussion}

Critical current density and dynamic modulus of shear of the deformed NT-50 sample were measured as a function of the annealing time. The measurement results are presented in the Figure.

It is seen from the Fig. that the $J_{c}(\tau)$ dependence has three stages: sharp critical current increase, raise to the plateau, and $J_{c}(\tau)$ decrease. It is important to note that the stage of $J_{c}(\tau)$ decrease appears at $\tau$ over $100 \mathrm{~h}$ (curve 1). If the entire cycle of optimum HT time determination is under consideration one should add the material annealing duration and the time expenses to measure $J_{c}(\tau)$ at different annealing stages. As a result of carrying out the $J_{c}(\tau)$ measurement cycles it has been established that the HT optimization procedure is long (the total time of HT optimization by $J_{c}(\tau)$ measurement is near $200 \mathrm{~h}$ ).

This time-limit includes the HT duration before the moment of $J_{c}$ value increase $(\sim 110 \mathrm{~h})$ and the total time of repeated $J_{c}$ measurements at different annealing stages $(\sim 90)$.

The $G(\tau)$ dependence (curve 2) shows a distinct maximum at $\tau=40 \mathrm{~h}$ that corresponds to the time of $J_{c}(\tau)$ raise to the plateau (curve 1). Comparison of the curves, presented in the Fig., permits to conclude that the HT duration increase to more than $40 \mathrm{~h}$ does not lead to the critical current density increase during the subsequent annealing. Consequently, according to $G(\tau)$ measurement results, the optimum TO regime can be limited by the time of reaching a maximum DMS value $(\tau=40 \mathrm{~h})$, and the subsequent annealing at the given temperature becomes useless. So, the presence of a maximum in the $G(\tau)$ curve, unlike the $J_{c}(\tau)$ dependence not having a distinct critical current, enables to end the annealing procedure at the $\tau$ value corresponding to the maximum in the $G(\tau)$ curve.

Note, that direct DMS measurements are carried out on a single sample, have not influence on the HT temperature regime and, consequently, do not elongate the total time cycle of the HT procedure not exceeding $40 \mathrm{~h}$. It has been noted, that for the case of HT optimization by $J_{c}(\tau)$ measurements the total time was of about $200 \mathrm{~h}$. Thus, the application of the $G(\tau)$ measurement method, as compared to the $J_{c}(\tau)$ measurement method, permitted to reduce

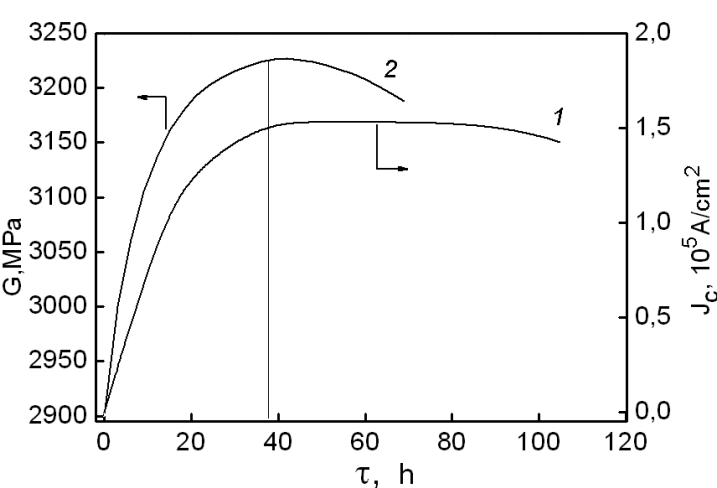

Fig. Critical current density (1) and dynamic modulus of shear (2) of the deformed NT-50 alloy as a function of heat treatment at $663 \mathrm{~K}$.

the total HT optimization cycle by a factor of 5 .

Let us consider the general causes of the maximum appearance in the $G(\tau)$ dependence. Nonmonotonic behavior of the $G(\tau)$ curve is due to the influence of the $\beta$-solid solution decay kinetics with the $\beta$-phase chemical composition changing at different stages of niobium-titanium alloy annealing. This permits to give a physical substantiation of the optimum HT temperature choice. We will proceed from the existing notions about the kinetics of HT decay of nonequilibrium solid solutions (including deformed alloys), according to which $[8,14-16]$ the peculiarity of the processes is the presence of three stages decay. The first stage is the formation of new-phase nuclei having subcritical size $R_{o}$, the second stage is the dissolving or growth of nuclei up to the critical stable size $R_{o c}$, the third stage is the coalescence of new-phase particles having the size $R>R_{o c}$. It is important to note that in the first- and the second decay stages, when the solid solution supersaturation is still high, the new-phase particles can grow via the bulk diffusion from the solid solution. In the third decay stage (the coalescence stage) the solid solution supersaturation by the second element is insignificant and formation of the new-phase particles with $R>R_{0}$ from the solution is, practically, stopped. And growth of the particles with $R>R_{o c}$ continues due to dissolving of the fine particles and growth of the coarse particles. Besides, in the third stage of solid solution decay formation of the new nuclei is, practically, excluded, as they should arise having already macroscopic sizes $[8,16]$. These observations are in 
agreement with our electron microscopic data: when $\mathrm{Ni}-\mathrm{Ti}$ alloy, deformed at $77 \mathrm{~K}$, is under annealing at $670 \mathrm{~K}$ during $10 \mathrm{~h}$ the $\alpha-T i$ particles of $200 \AA$ are formed that corresponds to the size of a nucleus with the stable critical size $R_{o c}$. Increase of the time of annealing at $670 \mathrm{~K}$ to $70 \mathrm{~h}$, leads to formation of $\alpha-\mathrm{Ti}$ particles of a minimum size of $500 \AA$ that is in agreement with the data of [15]. So, after completion of the first and the second stages of solid solution decay the titanium concentration in the $\beta$-solid solution was decreased and the niobium concentration was, respectively, increased, as compared with the $\beta$-state before annealing.

According to the data of [17] for $\mathrm{Nb}-\mathrm{Ti}$ alloys in the concentration range from 30 to $60 \%$ of $\mathrm{Nb}$ there is direct linear dependence between $\mathrm{Nb}$ amount in the $\beta$-phase and DMS value. Consequently, in our case the precipitation of titanium-containing phases during the solid solution decay in the firstand the second annealing stages should be accompanied by the DMS value increase because of the $\beta$-solid solution saturation with niobium that is experimentally observed (curve 2). The onset of the third stage (coalescence) corresponds to the maximum niobium content in the $\beta$-phase, as there is no titanium concentration decrease in the $\beta$ phase after ending of the first- and the second decay stages. Therefore, according to [17], the DMS value will not increase after the third stage onset. Furthermore, since in the coalescence stage the interphase boundary areas are changing, the alloy free energy increases and the $\alpha$-phase nuclei, of a size less than $R_{o k}$, partly dissolve in the $\beta$-matrix, the DMS value should decrease $[12,17]$. In our work we have observed this process, which reveals itself as a maximum in the $G(\tau)$ curve. The position of the maximum on the scale of $\tau$ corresponds to the instant when formation of the $\alpha$-phase particles with the sizes $R_{o}$ and $R_{o c}$ is stopped and very slow process of their coalescence begins. The slowing down of the solid solution decay process at the coalescence stage is explained by the fact that the reaction rates at the interphase surfaces are significantly lower than the rate of the dissolved element bulk diffusion in the matrix [1416]. Therefore, the coalescence rate is the slowest and the longest reaction.

The HT-formed structure corresponds to the optimum state of $\mathrm{Nb}-\mathrm{Ti}$ alloy with relation to the dispersion and concentration of the $\alpha$-phase providing maximum magnetic flux pinning and, consequently, the high values of $J_{c}$. It is important to note, that during the heat treatment of deformed niobium-titanium alloys the titanium depletion of the $\beta$-matrix occurs, that has to exert influence on the further $\beta$-phase decay intensity. Therefore, in the case of repeated plastic deformations and subsequent annealing one should keep in mind that after every stage of mechanical-thermal treatments the $\beta$-matrix composition can move towards niobium in the $\mathrm{Ni}-\mathrm{Ti}$ state diagram [17-19]. Thus, the titanium concentration in the $\beta$-matrix will decrease and, as a result, the kinetics, rate and composition temperature of the solid solution will change.

By measuring $G(\tau)$, it is possible to estimate not only the time parameters of HT and solid solution decay processes, but, also, to determine the amount of the $\alpha-T i$ phase at every HT stage using the dependence $G=G(\% \mathrm{Nb})$ of [17].

\section{Conclusions}

Thus, the analysis on the kinetics of phase transformations performed by the $G(\tau)$ measurement data shows the expediency of usage of "in situ" DMS measurement method to control the solid solution decay and to obtain the niobium-titanium alloys with desired superconducting properties. As the changes of the DMS have, as a rule, linear dependence on the second component percentage in two-phase solid solutions of different metals [12], the presented HT optimization technique can be used to estimate the decay kinetics for anyone of the twocomponent solid solutions.

\section{References}

1. O.V.Chernyi, Voprosy Atomnoj Nauki $i$ Tekhniki, Ser. "Vacuum, Chistye Metally, Sverkhprovodniki", 1, 10 (1999).

2. O.V.Chernyi, N.F.Andrievskaya, V.O.Ilicheva et al., Adv. Cryogen. Engin., 48B, 883 (2002).

3. O.V.Chernyi, G.E.Storozhilov, N.F.Andrievskaya et al., IEEE Trans. Appl. Superconduct, 15, 3502 (2005).

4. V.K.Aksyonov, O.I.Volchok, V.M.Gorbatenko et al., Fiz. Nizkikh Temper, 20, 595 (1994).

5. Ukrainien Patent 42487A (2001).

6. B.G.Lazarev, O.V.Chernyi, N.A.Chernyak et al., Cryogenics, 32, 593 (1992).

7. A.M.Campbell, J.E.Evetts, Critical Currents in Superconductors, Taylor and Francis Ltd., London (1972).

8. K.V.Chuistov, Metal Alloy Ageing, Naukova Dumka, Kiev (1985) [in Russian]. 
9. B.G.Lifshitz, Physical Properties of Metals, Mashgiz, Moscow (1959) [in Russian].

10. A.A.Galkin, V.I.Trefilov, V.P.Buryak et al., Metallofizika, 68, 55 (1977).

11. V.M.Azhazha, D.G.Malykhin, G.E.Storozhilov et al., Voprosy Atomnoj Nauki i Tekhniki, Ser. "Vacuum, Chistye Metally, Sverkhprovodniki", 4, 58 (2007).

12. M.L.Bernstein, V.A.Zaimovsky. Structure and Mechanical Properties of Metals, Metallurgiya, Moscow (1970) [in Russian].

13. I.A.Gindin, V.I.Kovalenko, V.S.Okovit et al., Zavodskaya Laboratoriya, 11, 1397 (1970).
14. I.M.Lifshits, V.V.Slyozov, Zh. Ehksper. Tekhn. Fiz,, 35, 479 (1958).

15. V.V.Slyozov, V.V.Sagalovich, Usp. Fiz. Nauk, 151, 67 (1987).

16. Yu.M.Ustyugov, Fiz. Metallov i Metalloved., 104, 570 (2007)

17. C.C.Koch, D.S.Easton, Cryogenics, 17, 7391 (1977).

18. G.N.Kadykova, Izv. Akad. Nauk SSSR, Metally, 3, 155 (1978).

19. G.N.Kadykova, I.V.Lyasotsky, Yu.D.Tyapkin, Izv. Akad. Nauk SSSR, Metally, 6, 199 (1975). 